\title{
Cangas ferruginosas: proposta pedagógica sobre a necessidade de conservação de um ecossistema ameaçado
}

\section{Ferruginous Cangas: pedagogical proposal about the conservation necessity of a threatened ecosystem}

\section{Cangas ferruginosas: propuesta pedagógica sobre la necesidad de conservación de un ecosistema amenazado}

http://dx.doi.org/10.21713/2358-2332.2016.v13.1011

Jalula Maria Lage Maciel, mestre em Ensino de Ciências pela Universidade Federal de Ouro Preto (UFOP) e professora de laboratório de Ciências do Centro Educacional de João Monlevade (CEJM), João Monlevade, MG, Brasil. E-mail: jalulalm@yahoo.com.br.

Flávio Fonseca do Carmo, doutor em Ecologia, Conservação e Manejo da Vida Silvestre pela Universidade Federal de Minas Gerais (UFMG) e coordenador do Instituto Prístino, Belo Horizonte, MG, Brasil. E-mail: flavio@institutopristino.org.br.

Luciana Hiromi Yoshino Kamino, doutora em Biologia Vegetal pela Universidade Federal de Minas Gerais (UFMG) e coordenadora do Instituto Prístino, Belo Horizonte, MG, Brasil. E-mail: luciana@ institutopristino.org.br.

Leandro Marcio Moreira, doutor em Bioquímica pela Universidade de São Paulo (USP) professor de Bioquímica e Biologia Molecular da Universidade Federal de Ouro Preto (UFOP), Ouro Preto, MG, Brasil. E-mail: Immorei@gmail.com. 


\section{Resumo}

A educação ambiental (EA), enquanto campo epistemológico, pode auxiliar no despertar da compreensão do papel do indivíduo no ambiente. Neste trabalho, apresenta-se o resultado da parceria entre o Mestrado Profissional em Ensino de Ciências da Universidade Federal de Ouro Preto e o Instituto Prístino, com o objetivo de desenvolver uma cartilha de EA, envolvendo o ecossistema de canga, para professores e alunos do ensino fundamental II. Em Minas Gerais, os ecossistemas ferruginosos - conhecidos como "cangas" - apresentam características abióticas que resultaram em um dos ambientes com maior endemismo vegetal do Brasil. Atuando como reserva hídrica que abastece mananciais da região metropolitana de Belo Horizonte, as cangas estão na lista dos ecossistemas mais ameaçados, em especial pela mineração. Este artigo fornece conceitos, peculiaridades, importâncias, ameaças e desafios, além de exercícios de fixação e discussão contextualizada, sendo, portanto, uma ferramenta diferenciada para o ensino de Ciências.

Palavras-chave: Educação Ambiental. Canga. Recursos Naturais. Mineração. Integração Universidade-Escolas. Cartilha.

\section{Abstract}

Environmental Education (EE), while an epistemological field, may assist to awake the comprehension of individuals' role within the environment. In this work, we present the result of a partnership between the Professional Masters Studies in Science Teaching from the Federal University of Ouro Preto and the Prístino Institute, aiming to develop an EE textbook involving the canga ecosystem for teachers and students of the basic education. In Minas Gerais, ferruginous ecosystems - known as "Cangas" - present abiotic characteristics that resulted in one of the environments with higher plant endemism in Brazil. Acting as a water reservoir that supplies water sources of the metropolitan region of Belo Horizonte, the Cangas are on the list of the most endangered ecosystems, especially by mining. This article provides concepts, peculiarities, 
importance, threats and challenges, in addition to fixation exercises and contextualized discussion being, therefore, a differentiated tool for Science teaching.

Keywords: Environmental Education. Canga. Natural Resources. Mining. University-Schools Integration. Textbook.

\section{Resumen}

La educación ambiental (EA), como un campo epistemológico, puede ayudar en el despertar de la comprensión del papel del individuo en el medio ambiente. En este trabajo presentamos el resultado de la colaboración entre la maestría profesional en enseñanza de Ciencias de la Universidad Federal de Ouro Preto y el Instituto Prístino con el objetivo de desarrollar una cartilla de EA sobre el ecosistema de canga para profesores y estudiantes de enseñanza fundamental II. En el Estado de Minas Gerais, los ecosistemas ferruginosos - conocidos como "cangas" - presentan características abióticas, que resultan en uno de los ambientes con mayor endemismo vegetal del Brasil. Ya que actúan como reserva hídrica, que abastece manantiales de la región metropolitana de Belo Horizonte, las cangas están en la lista de los ecosistemas más amenazados, en especial por la minería. Este artículo presenta conceptos, particularidades, importancia, amenazas y desafíos, además de ejercicios de aprendizaje y discusión contextualizada siendo, por lo tanto, una herramienta diferenciada para la enseñanza de Ciencias.

Palabras clave: Educación Ambiental. Canga. Recursos Naturales. Minería. Universidad-Escuelas. Cartilla.

\section{INTRODUÇÃO}

A questão ambiental, diante do molde socioeconômico de produção em massa, oriunda da revolução industrial, tem sido matéria de discussão constante (GOUDIE, 2000). As diversas atividades de 
produção proporcionaram à sociedade ganhos em desenvolvimento, porém, acompanhados de elevados custos. Os ganhos proporcionados pelos meios de produção dominantes culminaram com a apropriação dos lucros por uma minoria local, enquanto que os problemas ambientais resultantes foram socializados em escala global (DUTCH COMMITTEE FOR LONG-TERM ENVIRONMENTAL POLICY, 1994). As disparidades sociais e os consequentes impactos ambientais decorrentes do modelo hegemônico de desenvolvimento propiciaram problemas socioambientais (VANCLAY, 2003).

A educação ambiental (EA), enquanto campo epistemológico, surge nesse contexto com o propósito de fornecer subsídios teóricos, mas também como uma ação prática por meio da qual as pessoas se apropriam do mecanismo funcional do meio ambiente natural, dependendo dele, afetando-o e promovendo a sua sustentabilidade (DIAS, 2004). De acordo com o Artigo 225 da Constituição Brasileira de 1988, todos têm direito a um meio ambiente ecologicamente equilibrado, sendo esse um bem de uso comum do povo e essencial à sadia qualidade de vida. Com isso, a Constituição impõe ao poder público e à coletividade o dever de defender o meio ambiente e de preservá-lo para as presentes e futuras gerações (BRASIL, 1988).

Destarte, a promoção de uma sociedade consciente de suas ações, as quais geram consequências para o meio ambiente, torna-se matéria cada vez mais relevante e necessária. Isso coloca em evidência o desafio de atingir a reflexão dos seres humanos, sobretudo dos mais jovens e em formação, com o propósito de que, num futuro não muito distante, eles interfiram de forma positiva em suas relações com o ambiente. Dessa forma, o trabalho de educação e conscientização das futuras gerações que estão construindo seu entendimento de mundo se mostra como efetiva e fundamental via de atuação (HODSON, 2003). Ao encontro desse propósito, surgem os programas de pós-graduação em Ensino de Ciências ligados a instituições de ensino superior, cujo propósito de desenvolver pesquisas nessa área do conhecimento entra em consonância com a função de fornecer suporte e apoio às escolas de ensino básico. 
Este trabalho tem o objetivo de capacitar docentes da educação básica e fornecer subsídios para que os alunos tenham acesso a um conhecimento diversificado sobre ecossistemas brasileiros. Por meio da parceria entre o Mestrado Profissional em Ensino de Ciências (MPEC) da Universidade Federal de Ouro Preto (UFOP) e o Instituto Prístino foi elaborada uma cartilha que envolve o tema referente aos ecossistemas ferruginosos, também conhecidos como cangas. Essa cartilha é um produto com fins educacionais, desenvolvida com rigor científico, linguagem adequada e com qualidade gráfica. Ela permite a difusão do tema do meio ambiente em diferentes anos do ensino fundamental, servindo como material pedagógico suplementar aos livros didáticos.

\section{POR QUE CONHECER AS CANGAS?}

Embora o país apresente diversidade biológica ímpar, apenas os mais abrangentes ecossistemas são trabalhados e discutidos sob a perspectiva de ensino nas escolas nacionais: a Amazônia, a Mata Atlântica, o Cerrado, os Pampas e a Caatinga - estes três últimos campestres e aqueles florestais. Dessa forma, os ecossistemas em áreas restritas permanecem desconhecidos da sociedade, embora fundamentais ao ciclo da vida de muitas espécies e aos serviços ecossistêmicos relevantes (JACOBI et al., 2007). Entre os muitos fatores associados a esse desconhecimento, talvez um dos mais contundentes seja o negligenciamento no processo de difusão do conhecimento científico. Isso pode ter alguma relação com o atual sistema de avaliação das pesquisas e dos pesquisadores nacionais, embora ações afirmativas em divulgação e popularização científica tenham sido colocadas em prática pela Capes nos últimos anos. Ainda assim, é preciso aprofundar a reflexão sobre a popularização do ensino de Ciências (REGO, 2014).

Dentre esses ecossistemas negligenciados, as cangas merecem destaque. Quando recorrer ao dicionário ${ }^{1}$, o leitor irá encontrar os seguintes significados: "Peça de madeira que prende os bois pelo pescoço e os liga ao carro, ou arado; jugo"; "Opressão, sujeição, jugo"; "Pau que carregadores põem aos ombros para suspender fardos"; "Antigo instrumento de suplício
FERREIRA, Aurélio Buarque de Holanda. Novo dicionário Aurélio da Língua Portuguesa. Coordenação Marina Baird Ferreira, Margarida dos Anjos. $4^{\mathrm{a}}$. Edição. Curitiba: Editora Positivo, 2009. 
usado em parte da Ásia, formado por uma tábua com furos onde se prendia a cabeça e as mãos dos condenados"; "Certo tecido de algodão". No entanto, no contexto deste trabalho, a terminologia "canga" será abordada sob a ótica de um ecossistema desenvolvido junto da rocha ferruginosa. A palavra original, itapanhoacanga, datada do século XIX, sofre uma redução para a denominação atual e no dicionário o conceito relacionado é "concentração de hidróxidos de ferro na superfície do solo sob a forma de concreções, e que às vezes constitui um bom minério de ferro".

As cangas formam extensas couraças posicionadas como ilhas de ferro em meio a uma matriz geológica formada há bilhões de anos. Ela representa uma das superfícies expostas mais antigas do planeta. As couraças são compostas por até 90\% de óxidos e hidróxidos de ferro. A temperatura da superfície pode atingir quase $70^{\circ} \mathrm{C}$ e contém solos muito ácidos, rasos, com reduzidos índices de fertilidade (CARMO et al., 2012; CARMO; KAMINO, 2015).

No Brasil, quatro estados concentram a presença das cangas: a) Minas Gerais: nas regiões do Quadrilátero Ferrífero (QF), do vale do rio Peixe Bravo e da bacia do rio Santo Antônio; b) Pará: na região de Carajás; c) Bahia: no entorno do município de Caetité; e d) Mato Grosso do Sul: na região de Morraria de Urucum.

Devido às suas especificidades, o ecossistema ferruginoso apresenta elementos com características adaptativas e evolutivas singulares, como é o caso das plantas metalófilas, capazes de sobreviver em solos com elevado teor de metais (JACOBI; CARMO, 2008). Além disso, abriga espécies endêmicas e ameaçadas de extinção, contando também com vários tipos de habitats, como cavernas, capões de mata, fendas, lagoas (Figura 1A-C), entre outros (CARMO, 2010). 


\section{Figura 1 - Exemplos de habitats em cangas ferruginosas}
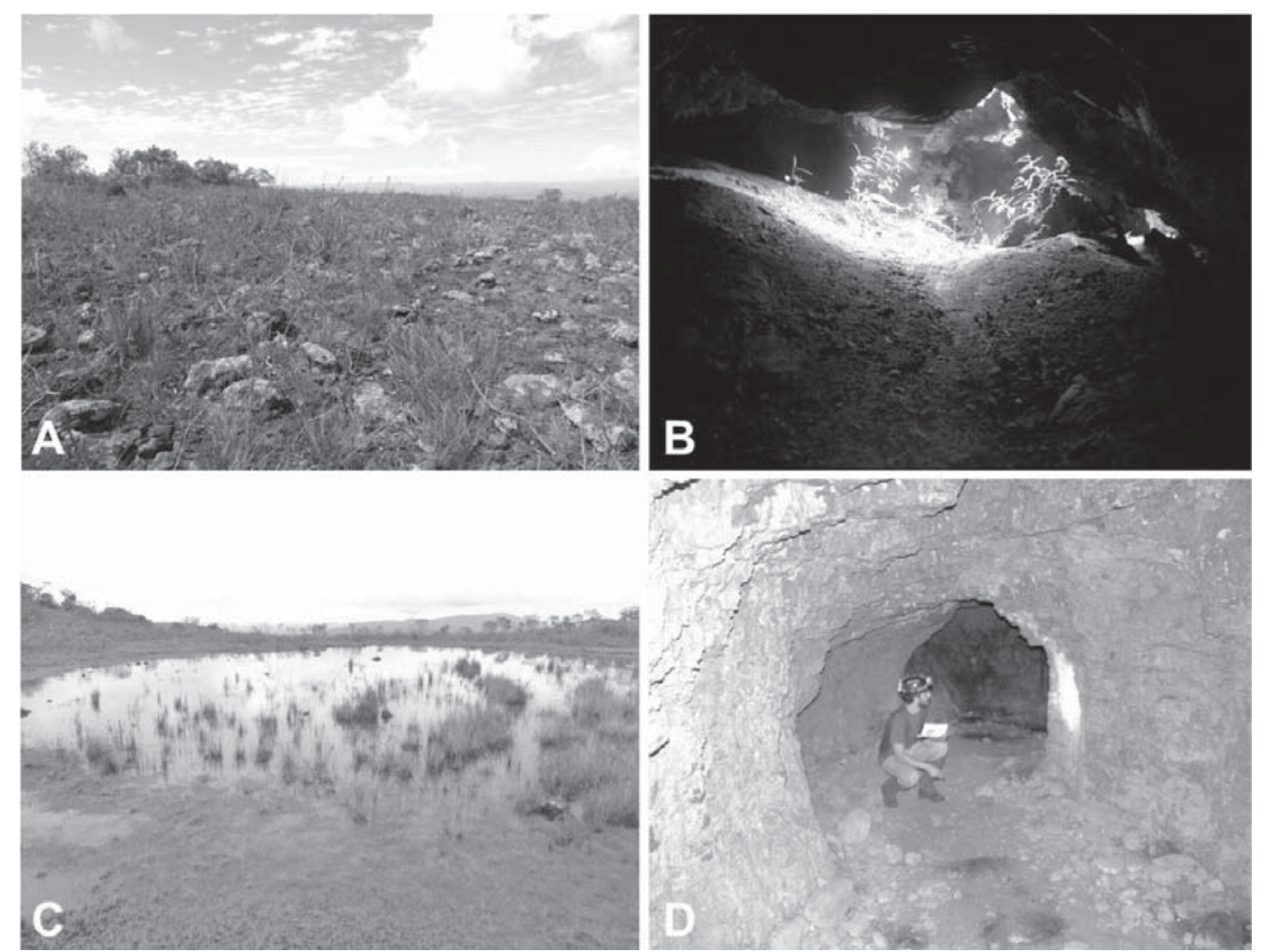

Fotos: Flávio Fonseca do Carmo.

Legenda: (A) vegetação característica crescendo sobre a couraça de ferro; (B) caverna associada às cangas; (C) lagoa associada às cangas; (D) paleotoca desenvolvida em rochas ferruginosas.

Registros arqueológicos foram identificados nas cangas como artefatos líticos e cerâmicos feitos por povos antigos, além de paleotocas (Figura 1D), que são estruturas em forma de túnel, escavados por animais extintos, provavelmente tatus e preguiças gigantes. Há ainda atributos históricos, dentre os quais se destaca a existência de ruínas dos séculos XVIII e XIX em trechos da Estrada Real. Outrossim, nesse ecossistema, ainda são encontradas muitas cavernas, que abrigam espécies com elevado valor para a conservação e para o conhecimento científico. Recentemente, foi descoberta em apenas uma dessas cavernas uma cigarra chamada Ferricixius davidii, classificada como um organismo troglóbio, ou seja, que sobrevive apenas em ambiente subterrâneo (FERREIRA et al., 2015), sendo então de vital importância a preservação de seu habitat.

Os serviços ecossistêmicos associados às cangas também são de extrema relevância ambiental, pois representam importantes áreas de recarga hídrica (OLIVEIRA; JACQUES; SHINZATO, 2005). Isso se deve 
pela enorme quantidade de poros, fendas, fissuras, canais e cavidades existentes nesses substratos ferruginosos, que funcionam como verdadeiras esponjas, logo transferem com eficiência a água da chuva para o interior das montanhas. Nos ecossistemas ferruginosos do QF, encontramos as nascentes dos rios Piracicaba, Santa Bárbara e Santo Antônio (Bacia do Rio Doce), dos rios das Velhas e Arrudas (Bacia do Rio São Francisco).

As cangas estão distribuídas em áreas restritas e associadas a importantes depósitos de minério de ferro, o que desperta interesse econômico em sua exploração. Ao mesmo tempo, as unidades de conservação de proteção integral ainda protegem uma parcela pouco representativa para a manutenção adequada dos processos ecológicos. Com o aumento da demanda por minérios, os impactos ambientais causados pela atividade da extração também tendem a aumentar. Esses impactos podem ser classificados como diretos, de alta magnitude, e irreversíveis, sendo que um dos mais graves está relacionado com a perda e a degradação dos habitats naturais. De acordo com Carmo et al. (2012):

As maiores jazidas podem ter extensão (perímetro linear) de $30 \mathrm{~km}$ e profundidade de 0,5 km, em geral alcançando o lençol freático. As cangas que recobrem a jazida são descartadas na extração do minério, feita com o uso de milhares de toneladas de explosivos. No processo de extração, o minério é beneficiado e o material restante, com baixo teor de ferro (chamado de estéril), é descartado e armazenado em pilhas enormes ao lado das cavas de extração. 0 processo de beneficiamento, por sua vez, quando feito por lavagem e peneiramento, gera o resíduo conhecido como "polpa", de aspecto semelhante à lama. No Brasil, o método mais comum para a deposição desta polpa são barragens de contenção, com frequência localizadas em vales naturais. Em muitos casos, a vegetação destes vales - quase sempre formações florestais associadas à rede de drenagem - é degradada ou suprimida.

As jazidas, portanto as principais cavas de extração, frequentemente estão situadas nos topos ou encostas de áreas montanhosas de onde partem densas redes hidrográficas. 0 próprio geossistema ferruginoso constitui um aquífero, com alta capacidade de recarga e armazenamento de água. Assim, o potencial de poluição ao longo de todo o sistema é bastante elevado, quando ocorrem alterações 
de grande magnitude nas partes mais altas do relevo (CARMO et al., 2012, p. 53).

No QF, recentemente, aconteceu o maior desastre ambiental do Brasil, e um dos maiores do mundo, devido ao rompimento de uma barragem de rejeito de minério de ferro, o que causou a degradação de mais de 600 km de rios, incluindo o rio Doce e sua foz no oceano Atlântico (FOLHA DE S. PAULO, 2016).

Portanto, com base nessas características geomorfológicas e biológicas, é importante pensar no uso responsável e racional dos recursos naturais associados às cangas. Destaca-se nessas áreas a possibilidade de obter grande quantidade de informações acerca de práticas, valores e estruturas das sociedades antigas, tornando sua preservação um importante meio de conservação do patrimônio de informações históricas. Todas essas informações científicas justificam a importância de estabelecer um diálogo com a sociedade, para que esta possa conhecer a importância das cangas num contexto biológico, mas também social e econômico. E a proposta de criação de uma cartilha contendo parte dessas informações se caracteriza como um dos passos objetivados pela equipe científica.

\section{A PARCERIA MPEC-UFOP E O INSTITUTO PRÍSTINO}

Por meio de uma associação entre docentes de quatro departamentos da UFOP, foi criada uma proposta diferenciada de mestrado profissional, cujo propósito era ofertar a professores das redes pública e privada, nos mais variados níveis de ensino, uma perspectiva de qualificação, diferentemente das propostas até então existentes em outras universidades. Assim, o MPEC apresenta um projeto interdisciplinar com linhas de pesquisa voltadas a três áreas do conhecimento: Ciências Biológicas, Química e Física, além das Ciências Humanas, que se correlacionam em todos os momentos a essas outras três áreas.

Uma das metas fundamentais do laboratório de Ensino em Ciências Moleculares, vinculado ao MPEC-UFOP, foi estabelecer parcerias com a 
sociedade civil organizada para o desenvolvimento de pesquisas. Para isso, estabeleceu uma cooperação científica com o Instituto Prístino. Criado em junho de 2012, o Instituto Prístino tem como objetivo promover a defesa e conservação do patrimônio natural, histórico e cultural. Além do uso racional dos recursos naturais, o instituto desenvolve pesquisas em diagnóstico ambiental e conservação da biodiversidade, oferece cursos de capacitação técnica, bem como prestação de apoio técnico-científico às instituições públicas. Entre as ações está ainda a socialização gratuita do conhecimento produzido pela ciência em uma linguagem de fácil entendimento pela sociedade.

Uma cooperação foi celebrada entre o MPEC-UFOP e o Instituto Prístino para desenvolver ferramentas de aporte pedagógico com o propósito de fortalecer o ensino de EA. O propósito central foi discutir sobre "a necessidade de conhecer para preservar", o uso racional dos recursos naturais e os impactos aos ecossistemas ferruginosos em decorrência da extração mineral. Essa discussão foi estimulada a partir do desenvolvimento e aplicação de uma cartilha voltada para professores e alunos do ensino fundamental II, cujos detalhes sobre a construção e avaliação serão apresentados a seguir².

\section{COMO SE DEU A CONSTRUÇÃO DA CARTILHA}

A elaboração de um ferramental de apoio para professores no ensino de Ciências é condição obrigatória para a conclusão do programa do MPEC e deve acompanhar a dissertação do aluno a ser titulado (Figura 2A). A Cartilha Canga representou esse produto.

Durante sua construção, além da obrigatoriedade de serem trabalhados os conceitos científicos associados ao tema focal, de forma clara e precisa, a principal preocupação da equipe era tornar a cartilha atrativa aos alunos da educação básica. Para isso, um diálogo preliminar

2 A versão digital concluída da cartilha estará disponivel gratuitamente no endereço: http://www.institutopristino. org.br/ foi estabelecido, na tentativa de compreender como os alunos teriam melhor aproveitamento do aprendizado. A solução se deu a partir de uma demanda proveniente dos alunos de uma escola pública de João Monlevade (MG), na qual a mestranda do MPEC Jalula Maria Lage Macia atuava como 
docente. Quando questionados sobre a maneira com a qual gostariam de aprender, alunos do $6^{\circ}$ a $9^{\circ}$ anos responderam, majoritariamente, "Com aulas interativas!", "Com diversão!," "Fazendo atividades!" e "Dialogando!". A partir do desafio em satisfazer esses desejos, a elaboração da cartilha foi estabelecida como base em avaliação e interação, no intuito de que o aprendizado ocorresse em uma relação horizontal, dialógica e recíproca (BORGES; ROCHA FILHO; BASSO, 2008). Nesse contexto, o aluno terá a oportunidade de conhecer e compreender sobre o conteúdo, além de refletir a respeito da intervenção sobre a realidade em que está inserido (SANTOS, 2007). Dessa forma, privilegia-se o desenvolvimento de sua autonomia e moral (RASERA; NARDI, 2010).

\section{Figura 2 - Componentes da cartilha}
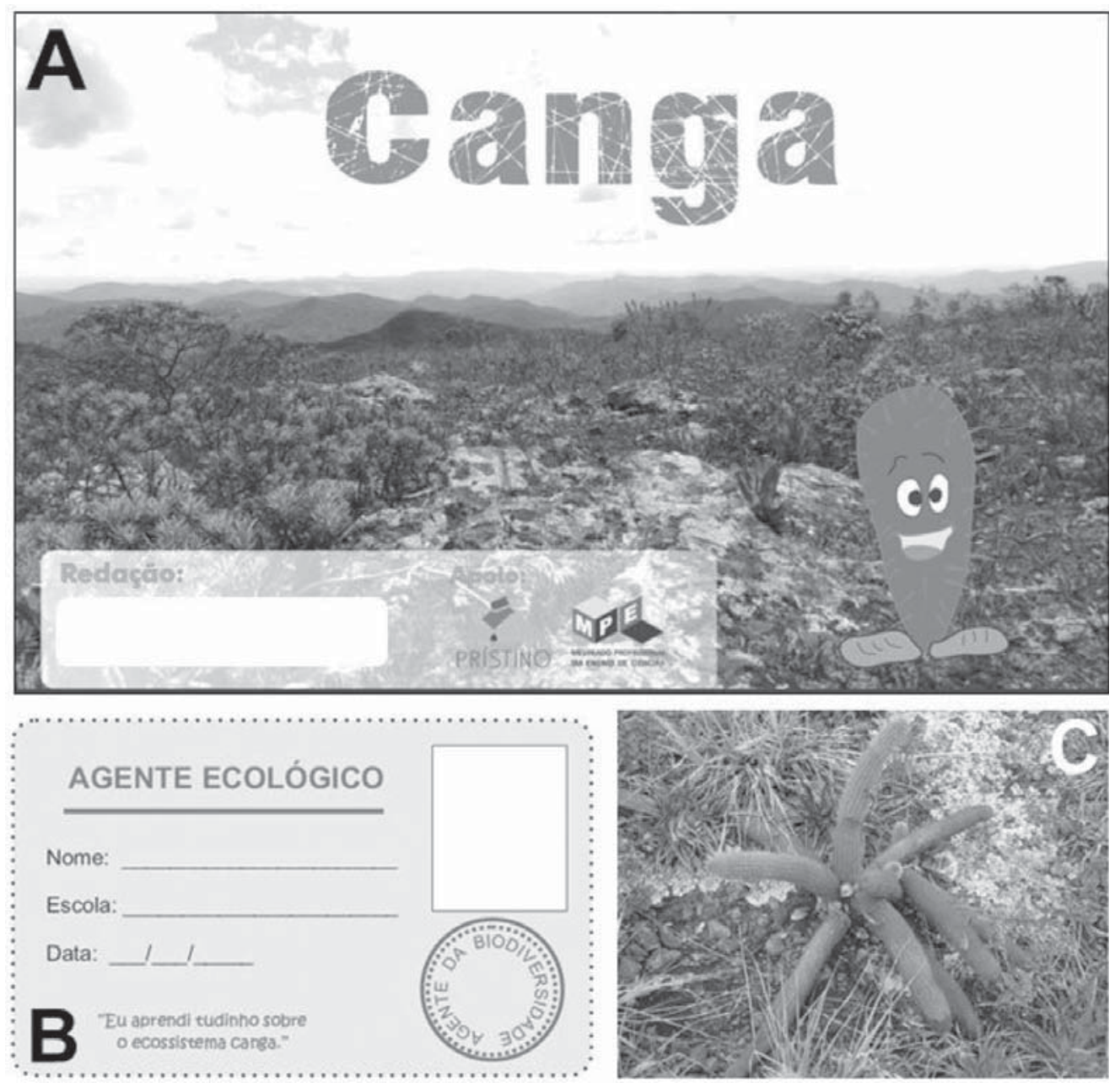

Fotos: Flávio Fonseca do Carmo.

Legenda: (A) capa da Cartilha Canga com o signo Ecocereus em destaque; (B) carteirinha de agente ecológico como parte integrante da cartilha; (C) Arthrocereus glaziovii, uma planta endêmica das cangas ferruginosas, símbolo do empenho ao desenvolvimento da cartilha. Nota: A carteirinha representa uma premiação a quem participa das atividades da cartilha, pois se torna um agente ecológico. A premiação é uma forma de estimular o empenho e a dedicação. 
Em um segundo momento, foi realizada uma pesquisa a respeito dos subtemas que seriam associados ao tema focal. Por meio de sugestões dos alunos, os textos para cada temática foram elaborados pela equipe técnica (MPEC-Prístino). Estes eram sempre acompanhados de atividadese ilustrações que reproduzissem em muitos aspectos a realidade do contexto no ecossistema de canga. Com a perspectiva de tornar o material adequado à linguagem dos alunos, escolheu-se uma personagem para protagonizar, explicar e apresentar esses atributos, permitindo intensificar o significado dos conceitos e dos temas abordados. Denominado "Ecocereus", a personagem representa um signo desenhado a partir das características morfológicas de uma espécie de cacto endêmico e ameaçado de extinção, visualizados apenas nas cangas do QF, o Arthrocereus glaziovii (Figura 2B). Por isso a denominação Eco = Ecologia e cereus = Arthrocereus.

Com o propósito de retribuir o empenho dos alunos, ao final da cartilha, uma carteirinha destacável foi elaborada para instituir o status de agente ecológico ao discente participante. Finaliza-se assim a composição dessa cartilha (Figura 2C). Isso permitiu a cada estudante concluinte dos estudos da cartilha assumir seu papel de agente ecológico. Assim, ele se torna um propagador de conhecimento científico e um defensor das cangas.

Desde a primeira até a versão final, a participação e o envolvimento dos alunos diante do material apresentado foram utilizados como recursos de melhoria de formatação e redação do conteúdo trabalhado para a conclusão do material proposto. Para a diagramação final e estruturação das ilustrações da cartilha, um profissional prestador de serviços foi contratado. Com o material finalizado e impresso, deu-se então a aplicação da cartilha e avaliação do seu potencial como descrito a seguir.

É importante destacar que o desenvolvimento da cartilha não se insere num projeto de código aberto (open source project). Desta forma, não há a possibilidade de o usuário contribuir com a edição da cartilha, embora possa sugerir modificações, comunicando-se com a equipe que a desenvolveu. Embora a proposta de desenvolvimento da cartilha tenha se findado com sua conclusão, as ações de divulgação científica desenvolvidas 
pela parceria supracitada terão continuidade em outros projetos de ação educativa, a exemplo de palestras e eventos de capacitação docente já estabelecidos pelo Instituto Prístino e seus parceiros.

\section{AS POTENCIALIDADES DA CARTILHA COMO FERRAMENTA PEDAGÓGICA}

A sequência dos assuntos abordados na cartilha foi elaborada a partir de temas sugeridos pelos alunos, mas regida pela equipe técnica por uma lógica de aprofundamento e correlações temáticas. A cartilha é composta por uma breve introdução sobre a personagem Ecocereus, seu estilo de vida e onde é encontrada. Nas páginas seguintes, encontra-se a essência da palavra "canga", seu significado e a abordagem sobre esse ecossistema único. Compõem o material os conceitos de "solo", "água", "flora" e "fauna". Todos abordados com linguagem simples e sempre acompanhados de dicas que procuram destacar e explicar algum tema específico para que o leitor possa se manter atento ao texto. Mais ao final da cartilha, as principais ameaças às áreas de canga, a importância das unidades promotoras de conservação desse ecossistema e os conflitos relacionados ao Parque Nacional da Serra do Gandarela são apresentados.

Dessa maneira, da forma como foi estruturada, a cartilha fornece ao professor ou tutor, que busca introduzir o assunto em sala de aula, a potencialidade de estabelecer uma proposta hierárquica, mas também integrada, de ensino, como representado pelo mapa da Figura 3. Mesmo que a cartilha retrate as relações muito bem estabelecidas entre conceitos fundamentais e tema focal, a dinâmica de aula, o interesse dos alunos e a disposição dos professores-tutores podem nortear a expansão das temáticas a serem trabalhadas. Logo, essa cartilha passa a ser utilizada inclusive como uma proposta de livro paradidático. 


\section{Figura 3 - Mapa hierárquico de conceitos que podem ser trabalhados a partir do tema focal "cangas ferruginosas"}

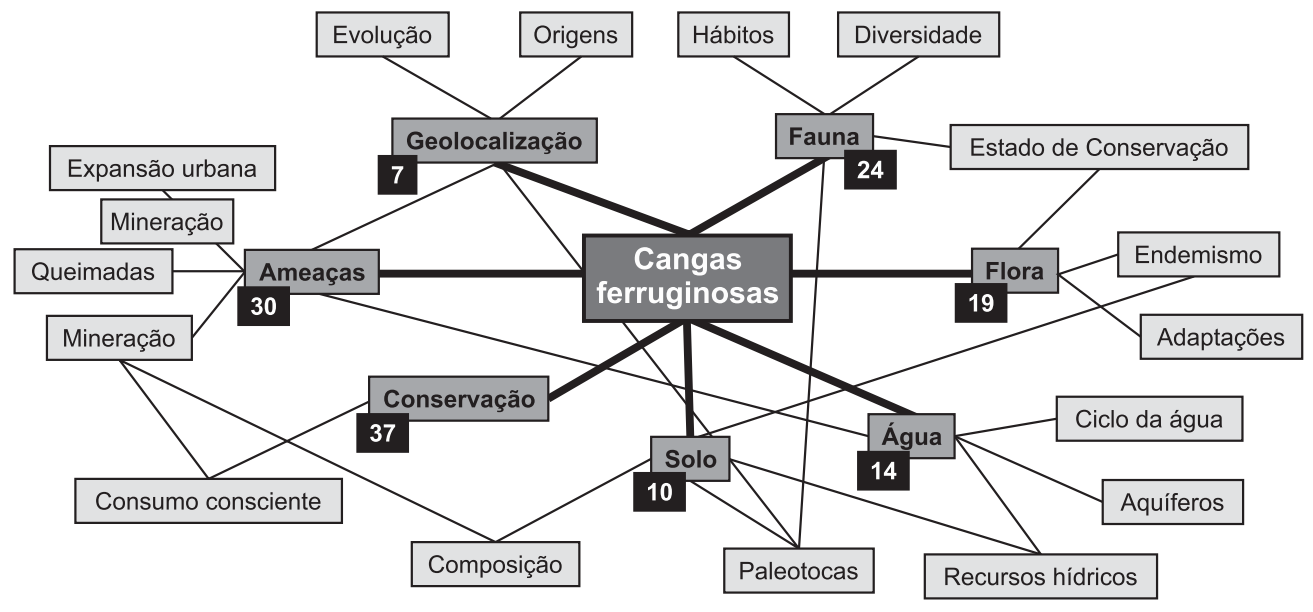

Educação Ambiental / CTSA / Interdisciplinar

Fonte: Elaboração própria.

Nota: Os subtemas associados ao tema focal são evidenciados em cinza escuro, com destaque para a página da apostila em que o tema se inicia (em preto). Outros conceitos e temas geradores (cinza claro) se originam a partir desses subtemas, os quais podem ser utilizados de diferentes formas pelos docentes que queiram fazer uso da cartilha.

Outra potencialidade da cartilha é a diversidade de tarefas de fixação e investigação presente ao longo de suas páginas. Estas colocam em evidência a discussão e reflexão sobre o conhecimento científico e suas ações práticas ora pela presença de perguntas abertas, ora pela simples oportunidade dada ao aluno para que expresse sua opinião textualmente ${ }^{3}$.

A partir das respostas oriundas dessas questões ou opiniões, os professores certamente deparar-se-ão com diversas possibilidades de aprofundamentos, que permitam os alunos participarem ativamente da aula, dialogando e socializando o conhecimento.

\footnotetext{
3 "O que você ou sua família têm feito para economizar água?" "Redija um pequeno texto explicando por que, em sua opinião, é importante proteger estas áreas onde são encontradas as paleotocas." "Você acha que estamos usando racionalmente os recursos naturais presentes nesta região? Dê sua opinião." "Se você tivesse o poder de criar uma lei ambiental para prevenir paisagens como esta, o que você sugeriria?"
}

Ao mesmo tempo, e de uma forma geral, a cartilha ainda traz consigo galerias de fotos da flora, fauna e unidades de conservação associadas às cangas ferruginosas, para que o leitor aprecie a beleza e a importância desse ecossistema num contexto mais amplo (Figura 4).

Pelo fato de algumas das espécies presentes nas galerias serem endêmicas e a maioria apresentarem risco elevado de extinção, outra potencialidade fica evidenciada: a de instigar os alunos a refletirem sobre 
a beleza e a importância desses seres vivos no ecossistema e sobre as ações que estão os dizimando. Isso permite ao aluno participante refletir sobre o uso consciente dos recursos naturais, colocando em evidência a importância de cada indivíduo (leitor) no processo de preservação do meio ambiente.

\section{Figura 4 - Galerias de fotos obtidas em regiões de cangas ferruginosas}

A

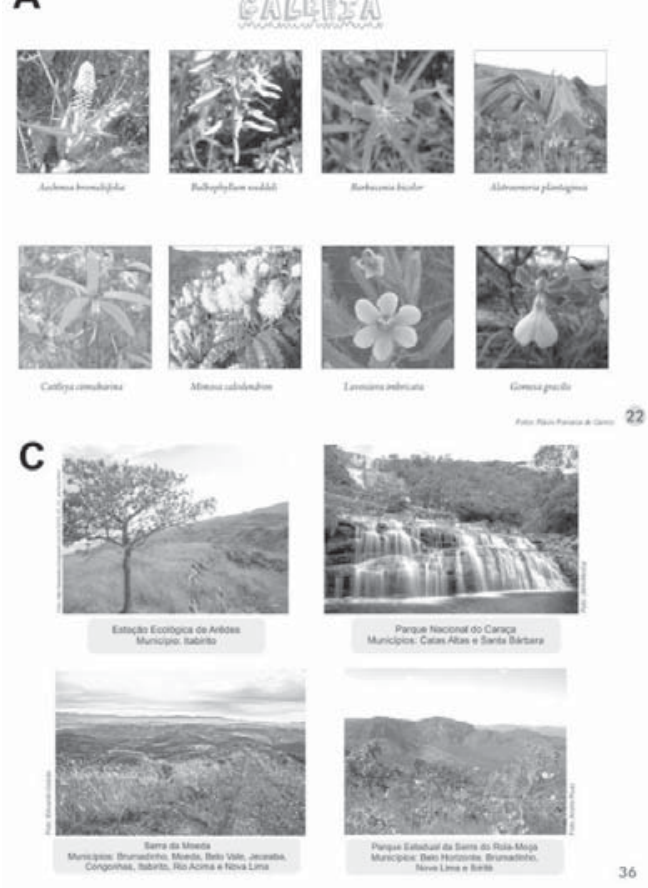

B

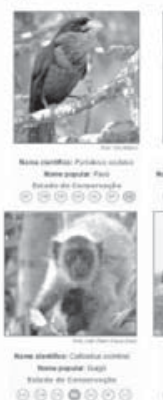

D
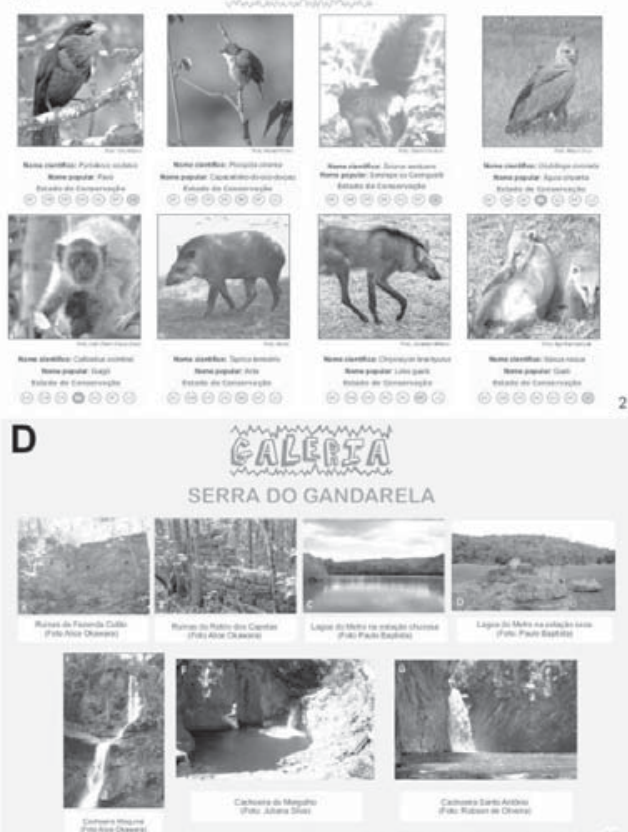

$-1$

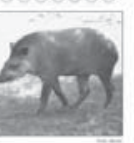

$=1$

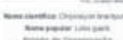

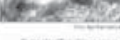

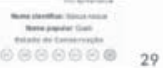

EAREREL

SERRA DO GANDARELA
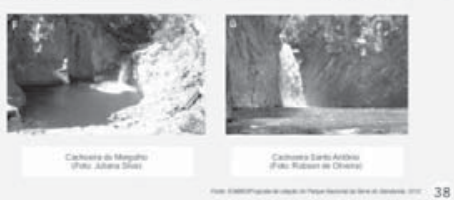

Fonte: Elaboração própria, adaptado de Maciel, 2015.

Legenda: (A) galeria de flora associando as imagens aos nomes científicos das espécies, todas endêmicas de canga; (B) galeria de fauna destacando o nome científico e o atual status de risco; (C) galeria de fotos das estações ecológicas e parques que agregam ecossistemas de canga em sua composição; (D) galeria paisagística da Serra do Gandarela.

Num contexto mais amplo, embora a cartilha tenha sido desenvolvida para alunos do ensino fundamental II, acreditamos que ela tenha um forte apelo para ações de capacitação de professores de toda a educação básica. Muitos dos conceitos e discussões presentes na cartilha fazem parte das propostas curriculares de ensino de Ciências e podem ser trabalhados em outros níveis de ensino, dadas as devidas adaptações linguísticas e investigativas. Além disso, o material pedagógico desenvolvido pode ser aplicado por educadores ambientais ao longo das atividades realizadas em unidades de conservação que abrigam as cangas ferruginosas, como, por exemplo, o Parque Estadual da Serra do Rola- 
Moça, o Parque Nacional de Gandarela, o Parque Municipal Mangabeiras e a Estação Ecológica de Arêdes. Algumas dessas áreas protegidas já recebem escolas ao longo do período de visitação, com desenvolvimento de atividades educativas.

\section{AVALIAÇÃO DA QUALIDADE}

Apesar de a aplicação da cartilha se restringir a um conjunto pequeno de alunos (37), em uma proposta piloto, sem uma avaliação qualitativa ou quantitativa criteriosa sobre o seu potencial e uso, o retorno desses envolvidos mediante respostas de entrevista semiestruturada refletiu a qualidade objetivada pela equipe MPEC-Prístino. Para a equipe multidisciplinar da escola em João Monlevade, a elaboração e aplicação da cartilha mudaram o comportamento e a rotina escolar durante o processo. Destacou-se também sua interferência no hábito dos alunos.

\section{PERSPECTIVAS FUTURAS}

Pelos resultados preliminares apresentados e por se tratar de um material diferenciado ao ensino de EA envolvendo o ecossistema de canga, duas ações conjuntas e congruentes foram instituídas para serem implementadas em curto espaço de tempo, como propostas de continuidade científica pela equipe MPEC-Prístino: a) disponibilização da cartilha na íntegra via portal do Instituto Prístino para que qualquer docente possa fazer uso de seus recursos; e b) ampliação do número de escolas e alunos agraciados com a aplicação e avaliação orientada da cartilha. Isso permitirá promover uma futura avaliação quali-quantitativa da cartilha e de suas atividades com o devido rigor científico.

Numa perspectiva de médio prazo, há a pretensão de disponibilizar esse material impresso em parques ambientais que possuam as cangas em sua constituição (Parque Estadual da Serra do Rola-Moça, Estação Ecológica de Arêdes, Parque Estadual do Itacolomi, Parque Nacional da Serra do Gandarela, Parque Municipal das Mangabeiras e Parque Serra 
do Curral) e que já possuam ou estão por implementar ações de visitação pública como uma alternativa potencial para difusão desse conhecimento científico. No mesmo contexto, essas versões impressas serão trabalhadas em escolas que carecem de recursos de informática ou acesso à rede mundial de computadores para obterem o arquivo digital.

\section{CONSIDERAÇÕES FINAIS}

A proposta deste trabalho se torna única pela divulgação desse ecossistema por meio da abordagem da produção de uma cartilha sobre as áreas de canga, trazendo para as novas gerações sua importância enquanto área de recarga hídrica e habitat de espécies endêmicas. Ao mesmo tempo, essa cartilha coloca em perspectiva de discussão e reflexão as ameaças à integridade do ecossistema de canga, uma vez que ocorre ação exploratória da mineração desenfreada, fruto de um consumismo exorbitante. Embora tenha um teor científico, o papel da cartilha vai além da simples transmissão de conhecimento. A cartilha corrobora a perspectiva de elaboração de outros materiais de apoio pedagógico que possam ser produzidos envolvendo outros biomas ou ecossistemas e que venham a contribuir para a EA, consequentemente, para uma futura preservação do meio ambiente.

Sob a perspectiva de importância das parcerias estabelecidas com o Instituto Prístino e com escolas de ensino básico, a cartilha reitera que estas podem ser bastante benéficas e produtivas, precisando ser incentivadas. A partir dessa reflexão, espera-se que programas de pósgraduação possam desenvolver propostas cada vez mais aplicadas à sociedade, pois a universidade é responsável direta pelo fomento das pesquisas, e usuária irrestrita de seu desenvolvimento.

Finalmente, mas não menos importante, a divulgação dessa proposta e os resultados desse projeto em meios de circulação científica colocam em evidência o produto e a parceria universidade-escolas no cenário nacional. 


\section{Agradecimentos}

Os autores agradecem os alunos, diretor, coordenadores de ensino e professores do Centro Educacional de João Monlevade pelo apoio e suporte no desenvolvimento da cartilha. Agradecem ainda o Instituto Prístino e o MPEC/UFOP pela oportunidade que a parceria estabelecida proporcionou para a realização da pesquisa, culminando com o presente artigo.

\section{Referências}

BORGES, R. M. R.; ROCHA FILHO, J. B.; BASSO, N. R. S. Avaliação e interatividade na educação básica em ciências e matemática. Rio Grande do Sul: EdiPUCRS, 2008. 184 p.

BRASIL. Constituição (1988). Constituição da República Federativa do Brasil. Brasília, DF: Senado Federal, 1988.

CARMO, F. F. Importância ambiental e estado de conservação dos ecossistemas de cangas no Quadrilátero Ferrífero e proposta de áreasalvo para a investigação e proteção da biodiversidade em Minas Gerais. 2010. 90 f. Dissertação (Mestrado em Ecologia, Conservação e Manejo da Vida Silvestre) - Universidade Federal de Minas Gerais, Belo Horizonte, 2010.

CARMO, F. F. et al. Cangas: ilhas de ferro estratégicas para a conservação. Ciência Hoje, Rio de Janeiro, v. 295, p. 49-53, 2012.

CARMO, F. F.; KAMINO, L. H. Y. Geossistemas ferruginosos do Brasil: áreas prioritárias para conservação da diversidade geológica e biológica, patrimônio cultural e serviços ambientais. 1. ed. Belo Horizonte: 3i, 2015. 551 p. v. 1.

DIAS, G. F. Educação ambiental: princípios e práticas. 9. ed. São Paulo: Gaia, 2004. 541 p. 
DUTCH COMMITTEE FOR LONG-TERM ENVIRONMENTAL POLICY. The environment: towards a sustainable future. The Hague: Kluwer Academic Publishers, 1994.

FERREIRA, A. B. H. Novo dicionário Aurélio da Língua Portuguesa. Coordenação Marina Baird Ferreira, Margarida dos Anjos. 4. ed. Curitiba: Positivo, 2009.

FERREIRA, R. L. et al. Biodiversidade subterrânea em geossistema ferruginosos. In: CARMO, F. F.; KAMINO, L. H. Y. (Orgs.). Geossistemas ferruginosos do Brasil: áreas prioritárias para conservação da diversidade geológica e biológica, patrimônio cultural e serviços ambientais. 1. ed. Belo Horizonte: 3i, 2015.

GOUDIE, A. The human impact on the natural environment. 5. ed. Cambridge, Massachusetts: The MIT Press, 2000.

HODSON, D. Time for action: science education for an alternative future. International Journal of Science Education, London, v. 25, n. 6, p. 645670, 2003.

JACOBI, C. M. et al. Plant communities on ironstone outcrops: a diverse and endangered Brazilian ecosystem. Biodiversity and conservation, Dordrecht, v. 16, n. 7, p. 2185-2200, 2007.

JACOBI, C. M.; CARMO, F. F. Diversidade dos campos rupestres ferruginosos no Quadrilátero Ferrífero. Megadiversidade, Belo Horizonte, v. 4, p. 2432, 2008.

MACIEL, J. M. L. Ecocereus e as multifunções ecológicas da canga: contribuições para educação ambiental. 2016. 135f. Dissertação (Mestrado em Ensino de Ciências) - Instituto de Ciências Exatas e Biológicas, Universidade Federal de Ouro Preto, Ouro Preto, 2016.

OLIVEIRA, G. S. R.; JACQUES, P. D.; SHINZATO, E. Projeto APA Sul RMBH: uso e cobertura da terra, mapas cobertura e uso da terra, escala 1:50.000. Belo Horizonte: SEMAD; CPRM, 2005. 
RASERA, J. C. C.; NARDI, R. Ensino de ciências e educação moral: uma interface de implicações mútuas. Revista Iberoamericana de Educación, Madrid, v. 53, n. 3, p. 1-12, 2010.

REGO, T. C. Produtivismo, pesquisa e comunicação científica: entre o veneno e o remédio. Educação e Pesquisa, São Paulo, v. 40, n. 2, p. 325346, 2014.

SANTOS, W. L. P. Contextualização no ensino de ciências por meio de temas CTS em uma perspectiva crítica. Ciência \& Ensino, Campinas, v. 1, 2007. Número especial.

TRAGÉDIA no Rio Doce. Folha de S. Paulo, São Paulo, 27 abr. 2016. Disponivel em: <http://www1.folha.uol.com.br/especial/2015/tragediano-rio-doce/>. Acesso em: 2 nov. 2016.

VANCLAY, F. International principles for social impact assessment. Impact Assessment and Project Appraisal, Guildford, v. 21, n. 1, p. 5-11, 2003.

Recebido em 30/04/2016 Aprovado em 03/10/2016 